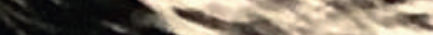

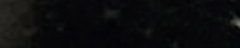




\title{
El trabajo de cine y video de Rafael Hastings
}

\author{
José-Carlos Mariátegui Ezeta \\ Alta Tecnología Andina \\ jcm@ata.org.pe \\ Lima-Perú
}

\begin{abstract}
[...] Dejar la televisión en manos del amigo de un ministro cualquiera, la foto-novela a cargo de escritores-publicistas, y la prensa al servicio del escándalo cotidiano necesario es una dimisión, una deserción para un revolucionario.
\end{abstract}

Rafael Hastings ${ }^{1}$

\begin{abstract}
Resumen
Este artículo intenta presentar la obra en cine y video del artista peruano Rafael Hastings (1945-2020), quien fue uno de los pioneros en experimentar con la imagen en movimiento dentro de las artes visuales en el Perú y Latinoamérica. Su obra videográfica y cinematográfica -desarrollada principalmente desde la mitad de los años 60 hasta principios de los años 80- ha sido poco estudiada, debido a algunas limitaciones en su acceso. A partir del escaso material audiovisual que existe, como documentos y testimonios, se puede descubrir los rastros de una rica y plurifacética producción, que evade las nomenclaturas artísticas establecidas y reta el trabajo historiográfico convencional.
\end{abstract}

Palabras clave: video arte, archivos, Perú, arte, film experimental, Europa

\begin{abstract}
This article attempts to present the work in film and video of the Peruvian artist Rafael Hastings (19452020). Hastings was one of the pioneers in experimenting with the moving image within the visual arts in Peru and Latin America. His video and film work - developed mainly from the mid-1960s to the early 1980s - has been little studied due to some limitations in access. From the scarce audiovisual material that exists, documents, and testimonies, it is possible to discover the traces of a rich and multifaceted production that evades established artistic nomenclatures and challenges conventional historiographic work.
\end{abstract}

Keywords: video art, archives, Peru, art, experimental film, Europe

El 30 de marzo del 2020, al inicio de la obligatoria cuarentena por el coronavirus, falleció Rafael Hastings en Lima. A lo largo de seis décadas, su obra cruzó disciplinas, prácticas y normas establecidas. Esta breve nota recoge principalmente su trabajo en cine y video, espacios en los que Hastings fue uno de los pioneros en experimentar con la imagen en movimiento dentro de las artes visuales en el Perú y Latinoamérica. Se trata de un trabajo aún poco

1 Extracto de texto inédito del artista (1970), reproducido en López, M. A. and R. Hastings (2014). Rafael Hastings: el futuro es nuestro y/o por un pasado mejor, 1983-1967. Lima: ICPNA, Instituto Cultural Peruano Norteamericano. 


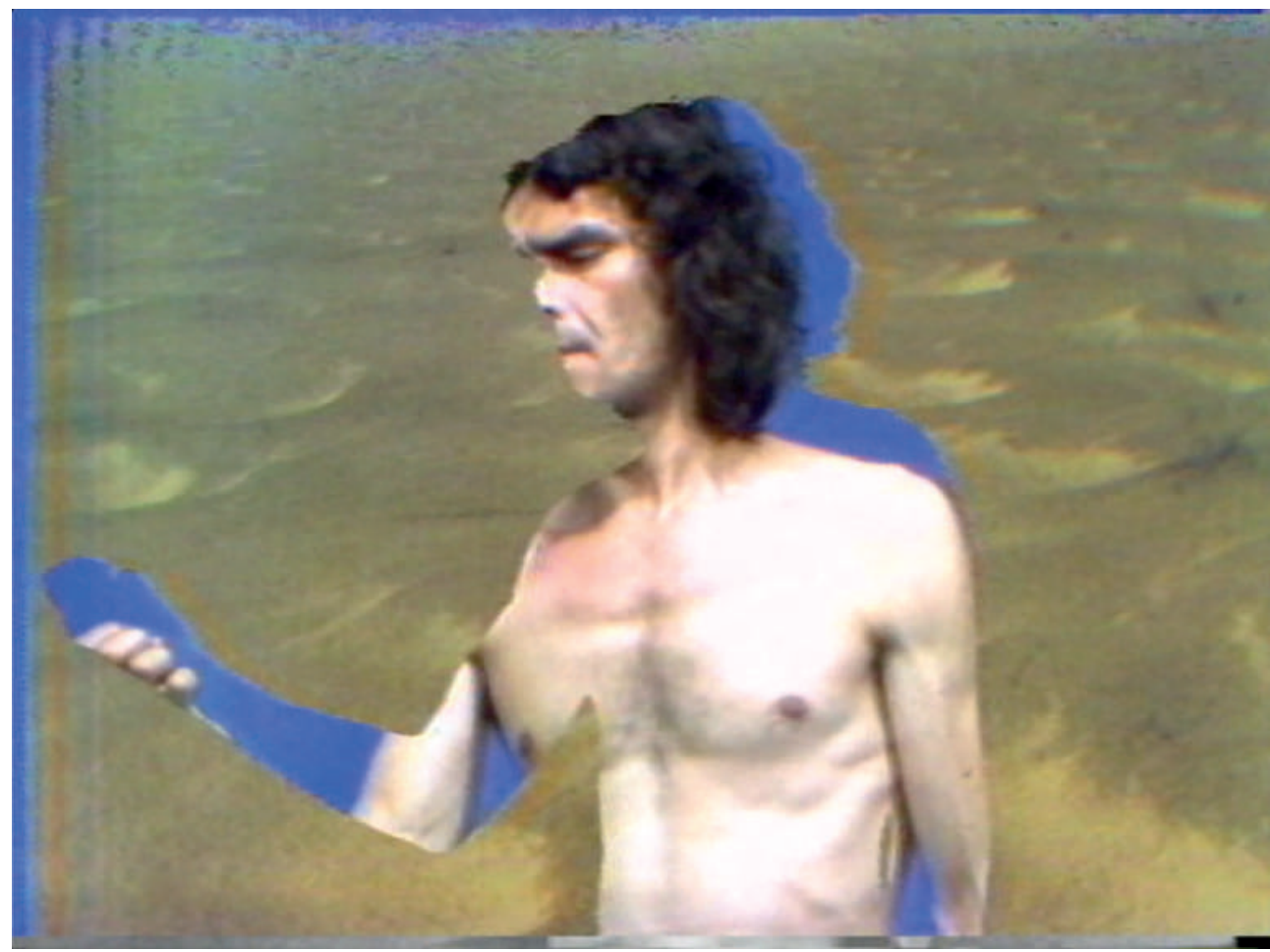

Rafael Hastings. El Canto de la tierra (Das Lied von Der Erde), 1978, 16 min

estudiado y fragmentado, y con ciertas limitaciones en su acceso -debido a que algunas de sus obras se encuentran perdidas-, y que como bien señala Miguel López, se expresa en "incursiones efímeras, proyectos y experimentos" (López y Hastings, 2014) por los que transitó Hastings, principalmente desde la mitad de los años 60 hasta principios de los años 80 .

Hastings fue un cosmopolita precoz. A los dieciséis años, durante su segundo año de estudios de Letras en la Universidad Católica, obtuvo una beca para realizar un viaje por siete meses al Estado de Israel -que tenía menos de dos décadas de formación-. Dicha experiencia marcó al joven estudiante peruano y, a su regreso a Lima, decide emigrar y continuar sus estudios en Europa. Llegó a Bélgica a fines de 1962, donde tras un breve paso por la Universidad de Lovaina decide continuar sus estudios en la Real Academia de Bellas Artes de Bruselas. Cultivó un ánima humanista e irreverente, gracias a la amistad con artistas e intelectuales provocadores, como Maurice Béjart -renovador de la coreografía contemporánea- y el escritor y director de cine François Weyergans, cuyo primer film en $16 \mathrm{~mm}$ fue precisamente sobre Béjart y provocó su expulsión del IDHEC (Hautes Études Cinématographiques), pues en aquel entonces los estudiantes estaban prohibidos de realizar películas profesionales.

En esos años, el uso artístico de la imagen en movimiento estaba en expansión, y Hastings empezó a realizar sus primeros experimentos, que consistían en pequeñas películas en primerísimos primeros planos de rostros. Los fotogramas los ensamblaba con una moviola que le habían regalado y luego los proyectaba entre amigos que estudiaban cine en Bruselas. 
En 1967 -con tan solo 22 años- tuvo su primera exposición individual en la Galerie Racines de Bruselas, la misma que fue presentada por el cineasta Jean-Luc Godard y Béjart (Noguera, 1967). Ese mismo año se muda a Londres, para realizar estudios en el Royal College of Art. En noviembre de 1967 regresa por algunos meses a Lima y presenta dos exposiciones. La primera, en el Instituto de Arte Contemporáneo (IAC), fue inaugurada con un concierto de New Juggler Sound, lo que llamó la atención del mesurado público limeño. La segunda muestra

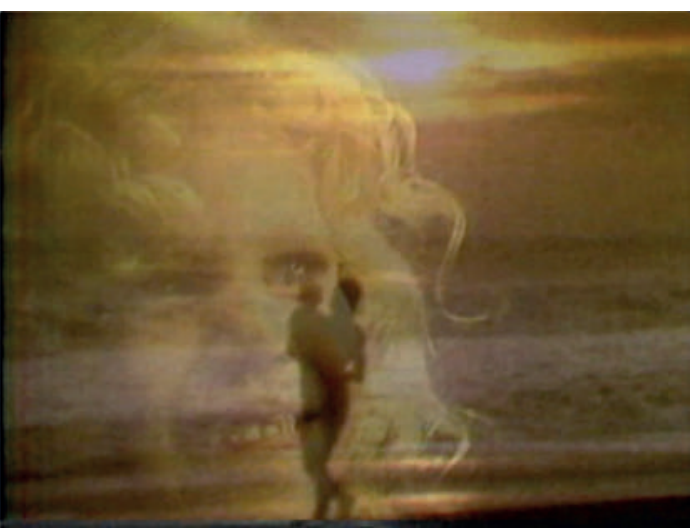

Rafael Hastings. Peruvian born, 1972-1978, 11 min tuvo lugar en la Galería Quartier Latin -dirigida por Mahia Biblos y Marie-

France Cathelat $-^{3}$ y se clausuró el 6 de marzo de 1968 con un happening. Concebido por Hastings como una revisión contemporánea del cuento infantil Blancanieves y los siete enanitos, consistía en una serie de raptos coordinados con anterioridad entre algunos de los asistentes al happening. Los raptos fueron realizados por un grupo de motociclistas que recorrían la vía expresa (Paseo de la República) hasta La Herradura en Chorrillos, para luego retornar al exterior de la galería. ${ }^{4}$

En su última etapa en Europa, Hastings vivió en París, por lo que fue influido intensamente por los movimientos estudiantiles y juveniles de mayo de 1968. Empezó en esa época a acercarse a la práctica teatral experimental (mezclada con escritura y performance) y al video. Gracias al lanzamiento de la cámara Sony Portapak, varios artistas, como Nam June Paik, Juan Downey o Andy Warhol, ya habían empezado a experimentar con el video, pues permitía mayor accesibilidad y facilitaba las técnicas de edición y reproducción de la imagen en movimiento. Con el apoyo de la productora parisina Agence Francaise d'Images (AFI), ${ }^{5}$ Hastings empieza a interesarse por las capacidades de abstracción interpretativa que permitía el video.

A su regreso al Perú a inicios de los años setenta, se involucra activamente en varios proyectos de producción audiovisual. Fue así como en 1973 establece contacto con Jorge Glusberg, fundador del Centro de Arte y Comunicación de Buenos Aires (CAYC), que impulsaba la internacionalización del arte latinoamericano. Glusberg ofrece su apoyo para producir What do you really know about fashion?, un "detrás de cámara” de situaciones inadvertidas

2 Se trataba de un grupo musical integrado por los hermanos Saúl y Manuel Cornejo, Eddy Zarauz, Alberto Miller y Alex Abad.

3 "En el "Quartier Latin": Exposición de Hastings". El Comercio, Lima 16 de febrero de 1968, p. 19. Por Juan Acha; "iHappening!", El Comercio, Suplemento Dominical, Lima 10 de marzo de 1968, pp. 30-31 por Luis A. Meza; "Habrá Happening: muestras en exhibición” El Comercio, Lima 5 de marzo de 1968, p. 19; "Happening en clausura de muestra" El Comercio, Lima 7 de marzo de 1968, p. 19.

4 Rafael Hastings mencionó en conversaciones con el autor de este artículo que el actor principal en dicho happening actuó luego en The Last Movie, película dirigida por Dennis Hopper ambientada en Chinchero en 1969. Es posible que el actor al que se refiere Hastings haya sido Bratzo Vicich, quien participó en The Last Movie, utilizando su moto de carreras para realizar piruetas frente a la plaza de Chinchero y luego raptarse a la protagonista (representando en un estilo benjaminiano al ángel del futuro, es decir, simbolizando la modernidad).

5 No se cuenta con mucha información sobre esta productora, pero por los pocos datos disponibles, esta sociedad fue fundada por la realizadora Renée Kammerscheit y el escritor Worms Roger (Roger Stéphane), y estuvo ubicada en 26 rue de L'Étoile en Paris. 

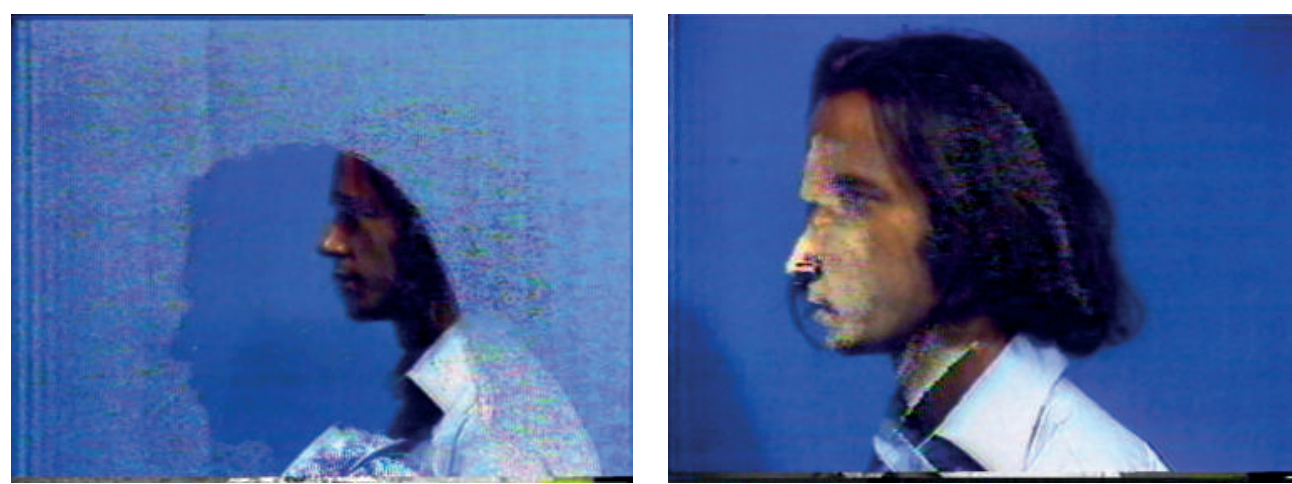

Rafael Hastings. Peruvian, 1978, 2 min

que transcurren durante un desfile de modas: "desde las etiquetas hasta las caídas, el sudor de las modelos: es decir todas las cosas que quedan ocultas en un show de este tipo" (López, 2014) intercaladas con textos en inglés que enfatizaban la observación crítica e irónica a partir de una estructura de identificación del proceso de comunicación que definía como "antologías" y se dividía en tres momentos: la actitud, el fenómeno y sus connotaciones. Para establecer el inicio de cada uno de estos tres momentos, una voz en off en inglés refería el momento mientras aparecían imágenes relacionadas. Hastings realizó este trabajo un lustro antes de que Andy Warhol produjese la serie de TV Fashion (1979), que también retrataba la fabricación de la belleza y la vida cotidiana del mundo del modelaje.

Es así que inicia una serie de colaboraciones con Glusberg, como la serie de 120 fotocopias Pompeya-Nueva York, exhibida en el CAYC en diciembre de 1973, y el video Anthologies (1974), ${ }^{6}$ proyecto que quedó trunco, aunque una versión preliminar fue presentada en un formato similar al de un videoclip y tuvo una amplia circulación internacional como parte de las muestras y los "International Open Encounters on Video" organizados por el CAYC (Cytlak 2017). ${ }^{7}$ Hastings también participa de la exposición Arte de Sistemas en América Latina organizada por el CAYC entre 1974 y 1976, que buscaba crear un modo de circulación internacional alternativo y eficiente, para, a partir de ello, redefinir las nociones que se tenían en ese entonces sobre el arte latinoamericano.

Muchos de los trabajos en video de Hastings fueron gestos de provocación frente al establishment del arte, pero también denotaban situaciones personales, cotidianas y espontáneas, que son recompuestas a partir del uso de técnicas de cine y video. Hola Soledad (1973), consistía en tres tomas donde capturó de manera espontánea el enfrentamiento -casi absurdo- entre un enfermo mental callejero y un cojo. El tema musical Hola Soledad de Palito Ortega, popularizado en aquel entonces por el cubano Rolando Laserie, fue escogido como fondo musical y título de la obra. We are not a family (1974) comprendía un recorrido -bajo la técnica de stop motion- por los diferentes espacios y objetos de su casa en Lima, antes y después de que esta fuera arrasada por el terremoto del 3 de octubre de 1974. Peruvian Born (1972-1978) es una alegoría simbolizada por los primeros años de vida de su hija Aiñari. La empezó a filmar en 1972, cuando su esposa, la coreógrafa Yvonne von

6 En los documentos hallados sobre esta obra menciona que tuvo las siguientes características técnicas y de duración: "Sony - American Standard - b/w - $12 \mathrm{~min}$ - $50 \mathrm{~Hz}$ - 1/2" open reel - sound" (aunque la información sobre la duración en algunos casos indica $5 \mathrm{~min}$ ).

7 Se tiene identificado que se presentó en el ICC (Internationaal Cultureel Centrum) de Amberes (1974), en la muestra Video-alternativo latinoamericano en el Museo de Arte Moderno de Nueva York (1974), y en la Galería Cívica de d’Arte Moderna en Ferrara (1975). 


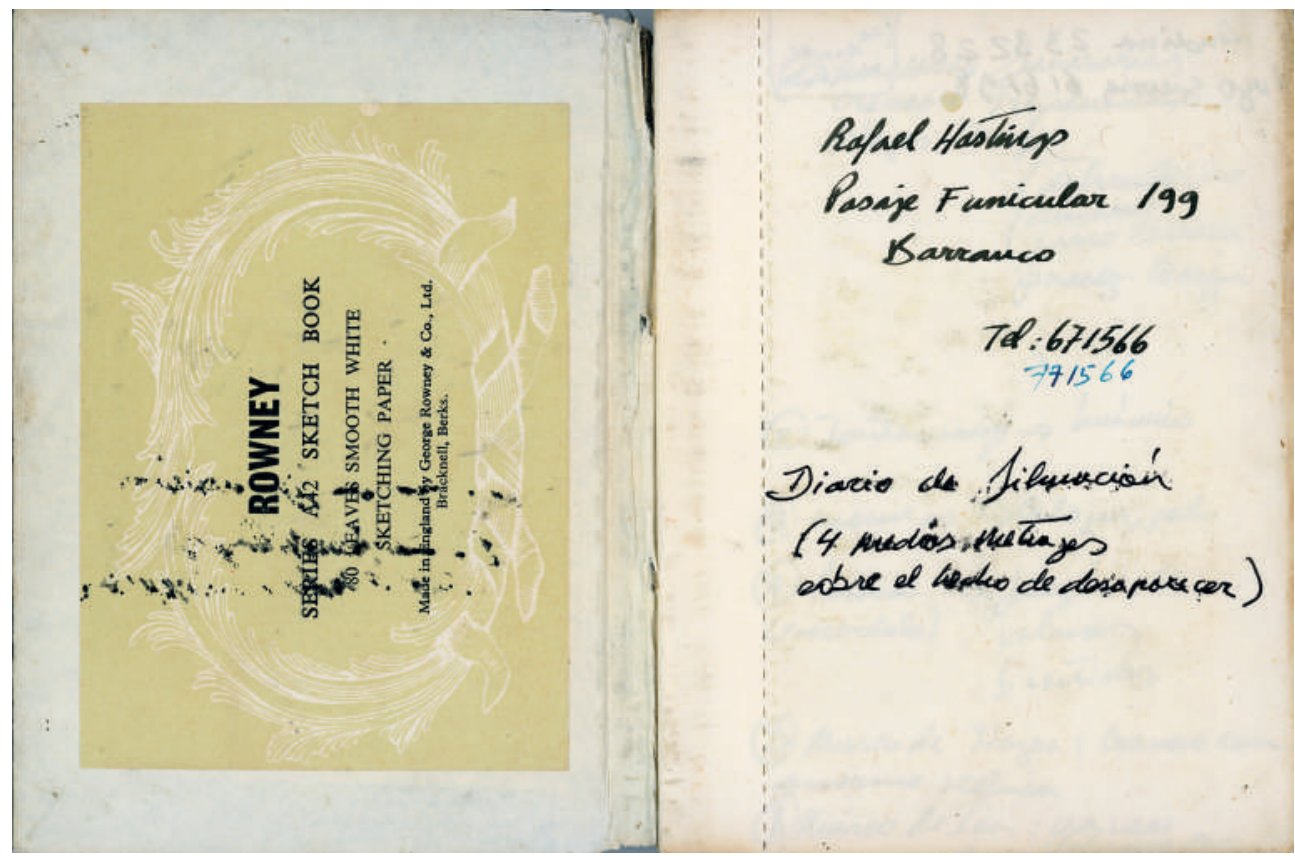

Rafael Hastings. Diario de Filmación, ca. 1974

Mollendorff, estaba embarazada de su hija Aiñari, y lo concluyó en 1978. Las etapas de vida son registradas en video y se superponen con el rostro asombrado de la niña a los cuatro años, mientras observa el avance de su propio desarrollo. Todas las imágenes fueron filmadas en una misma locación en Pachacamac.

En 1973, la Pontificia Universidad Católica del Perú (PUCP) fundó el Centro de Teleducación (CETUC), y Hastings empezó a hacer uso del estudio de fondo croma, que permitía experimentar con ciertos efectos especiales, novedosos en aquel entonces. Es así que en el CETUC desarrolló trabajos como Peruvian (1978), donde superpone varias versiones del rostro de su amigo, el músico y percusionista Manongo Mujica, mostrando las muchas imágenes que pueden derivar del registro de un movimiento siguiendo los cuatro puntos cardinales (de este a oeste y de norte a sur). En la misma línea, Das Lied von Der Erde (El canto de la Tierra) (1978), es una coreografía sobre el cuerpo del actor Ricardo Santa Cruz (de la compañía de teatro Cuatrotablas), donde por efecto de croma se superponían partes del cuerpo del actor, como el brazo y el puño. Las imágenes corporales eran superpuestas por un fondo de paisajes de la ciudad de Toulouse: edificaciones, castillos y ciudades registradas por Hastings y José Cassals, creando una artificialidad incuestionable, pero, a la vez, un intento precoz de poesía visual (Mariátegui, 2018).

En términos de difusión local, tanto Hola Soledad, como What you really know about fashion?, se presentaron en Lima durante el VIII Festival Internacional de Video Arte ${ }^{8}$ organizado

8 El número corresponde a las ediciones de dicho Festival, organizado previamente en ICA (Londres, diciembre 1974), Espace Pierre Cardin (Paris, febrero de 1975), Palazzo dei Diamanti (Ferrara, mayo de 1975), CAYC (Buenos Aires, noviembre de 1975), ICC (Amberes, febrero de 1976), Museo de Arte Contemporáneo (Caracas, enero 1977), Fundación Joan Miró (Barcelona, febrero de 1977), Galería del Banco Continental (Lima, setiembre de 1977), Museo Carrillo Gil (México D. F., noviembre de 1977) y Sogetsu Art Center (Tokyo, abril de 1978). 


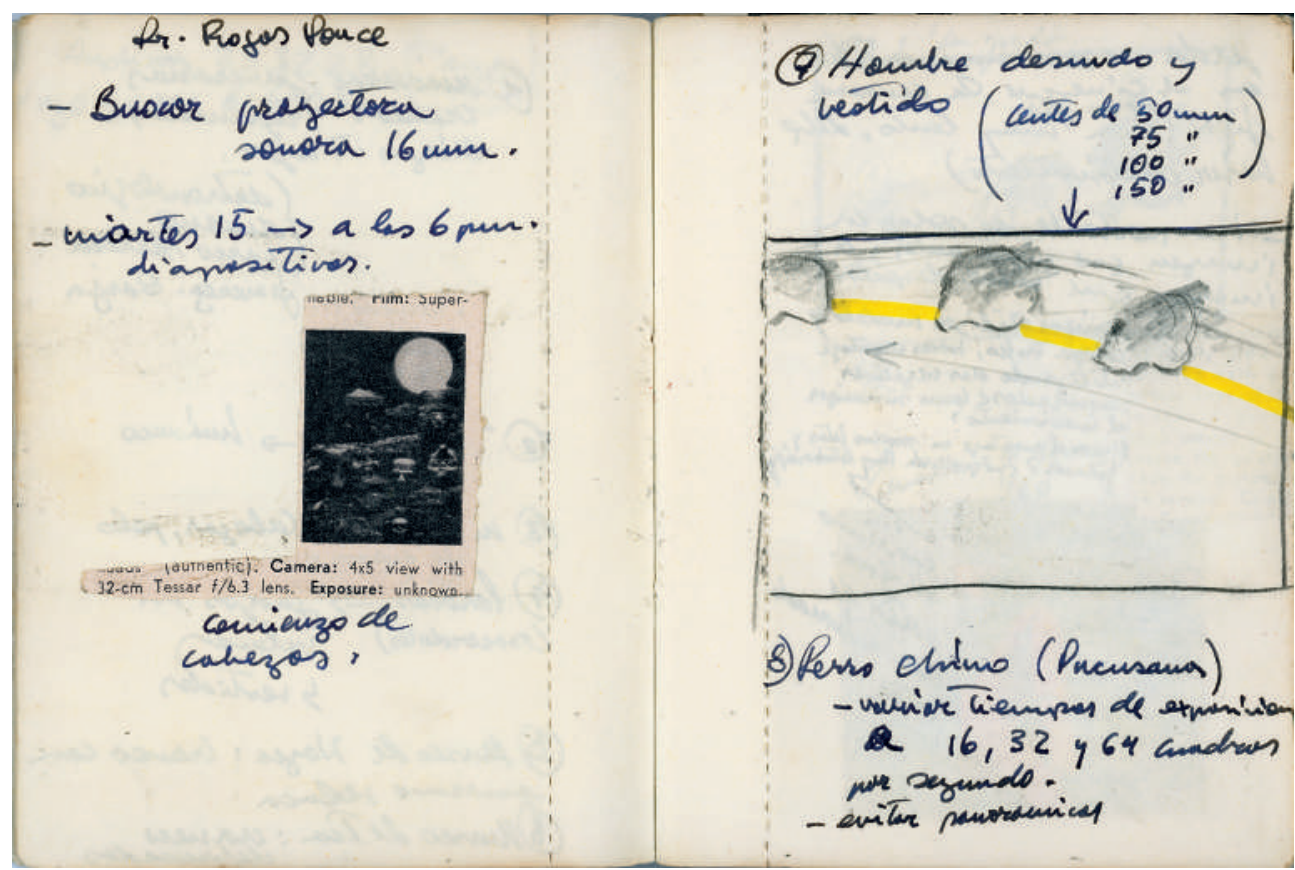

Rafael Hastings. Diario de Filmación, ca. 1974

por Alfonso Castrillón y Jorge Glusberg en setiembre de 1977 en la Sala de Exposiciones del Banco Continental (Lima), dirigida por Castrillón. A fines de los años noventa, Peruvian Born, Peruvian y Das Lied von Der Erde fueron transferidos de su formato original (U-Matic) a digital, lo que aseguró su preservación y difusión futura. Sin embargo, videos como What do you know about fashion?, We are not a family, Anthologies y Hola Soledad se encuentran aún desaparecidos, y la información acerca de su contenido está basada en entrevistas a Hastings y colaboradores, así como a partir de documentación en archivos en el Perú y el extranjero.

Además de sus trabajos en video, entre 1974 y 1976 Hastings realizó cuatro películas en $35 \mathrm{~mm}$. La primera, titulada En el Árbol del Mundo, llevaba como subtítulo Esta filmación puede ser considerada una obra de ficción en la medida en que la ficción hace parte de la realidad. Se trataba de una suerte de película de "divulgación científica", que narraba el proceso de fecundación a partir de una detallada filmación de una tela de la cultura Paracas, que graficaba simbólica y sutilmente dicho proceso.

El segundo proyecto, denominado Incondicionado Desocultamiento, consistió en una ambiciosa producción de tres mediometrajes que formaban una suerte de trilogía-largometraje. El proyecto giraba en torno a la muerte y al hecho de desaparecer, articulado a partir de una exploración en las culturas precolombinas, el desierto peruano y algunos conceptos mágico-religiosos. Su producción demandó un mes de viajes desde Tacna a Tumbes. Integraron el equipo de rodaje Jorge Vignatti (camarógrafo), Manongo Mujica (músico), Fernando Llosa Porras (especialista en temas arqueológicos vinculados con el simbolismo), y otros profesionales (como maquilladores, sonidistas y actores).

El diario de filmación realizado durante el viaje acopia aspectos importantes del proceso de realización de las películas, y nos permite entender cómo se organizaba el trabajo 


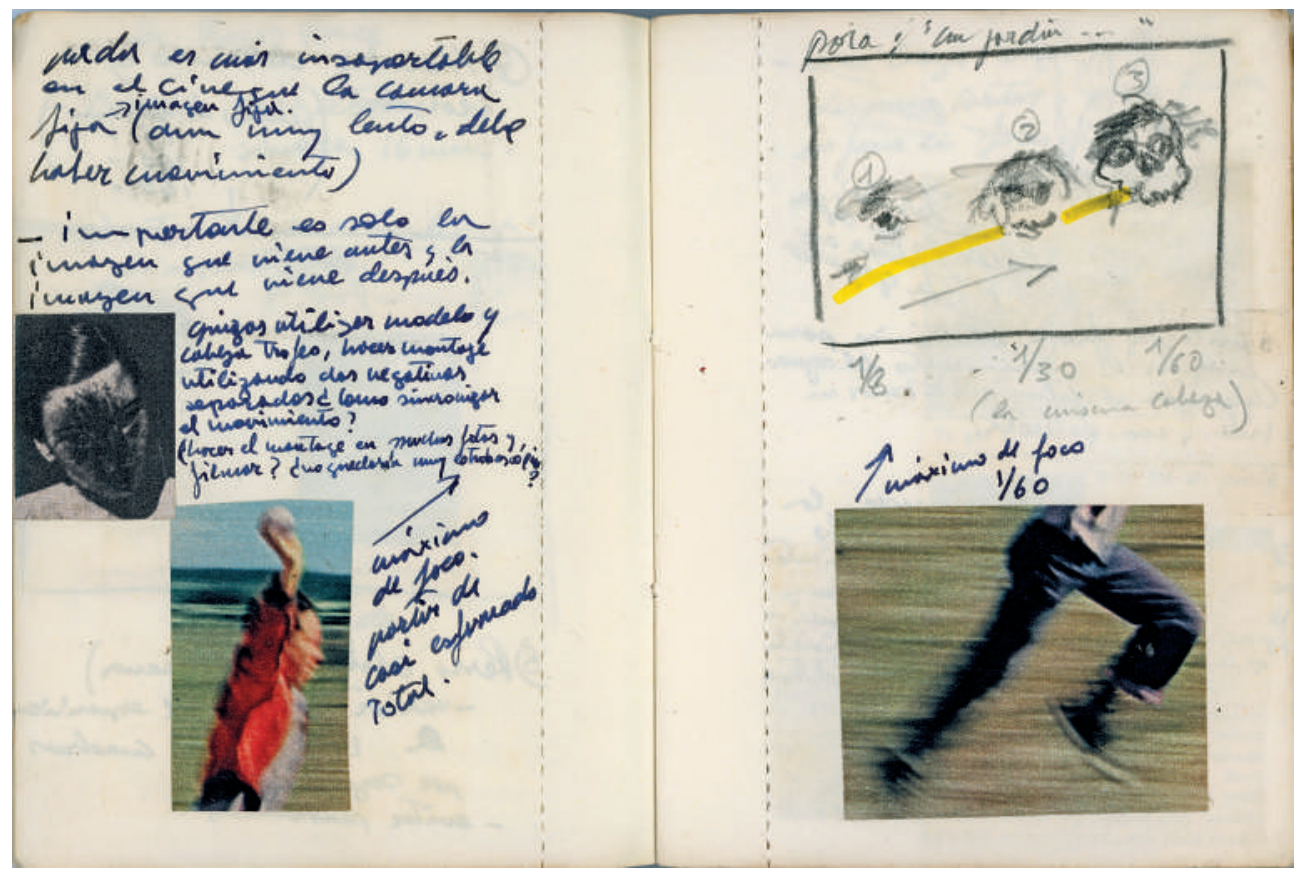

Rafael Hastings. Diario de Filmación, ca. 1974

creativo del autor. La libreta titulada Diario de filmación (4 mediometrajes sobre el tedio de desaparecer), ${ }^{9}$ recoge ideas, situaciones e "instantáneas", que acontecían a lo largo del periplo por la costa peruana, así como recortes de revistas de esa época, para explicar encuadres técnicos al camarógrafo. La libreta contiene dibujos y esquemas que se infiltran con colores de acuarela, produciendo figuras cuasi abstractas, a veces superpuestas por textos y poemas. Se trata de un dispositivo que le permitió a Hastings conectar la ficción visual con las técnicas necesarias para llevar a cabo sus ideas, similar al ejercicio realizado en la serie Dibujos mentales (1967-1968) (López y Hastings, 2014). La filmación no tenía un guion completamente definido, lo que permitía capturar el momento de forma vivencial y espontánea expandiendo la narrativa audiovisual, conforme exploraban el camino. Acercamientos extremos, close-ups, cámaras lentas, tiempos de exposición, velocidad de filmación (en cuadros por segundo) y otras referencias de técnicas cinematográficas permitían vislumbrar en el papel ese momento-instante, o lo que Walter Benjamin llamaba el "inconsciente óptico" (Benjamin, 1986).

Las referencias y terminologías anotadas en la libreta señalan un conocimiento significativo sobre técnicas de producción fílmica, que le permitían a Hastings especificar con claridad ciertos detalles en relación con las tomas, como las variaciones de tiempos de exposición, velocidades (16, 32, 64 cuadros por segundos) o el uso del "flash electrónico", para congelar el movimiento del agua. Hay momentos donde la descripción técnica se transforma y abraza el relato poético, como cuando anota: "Contrast is dramatic when two complementary colors red and green, blue and orange or yellow and violet are placed in juxtaposition" (El

9 El autor de esta nota agradece a Rafael Hastings por haberle obsequiado esta libreta en octubre de 2019. Nótese que se indican que fueron cuatro mediometrajes, pero según testimonios de los protagonistas fueron tres. 


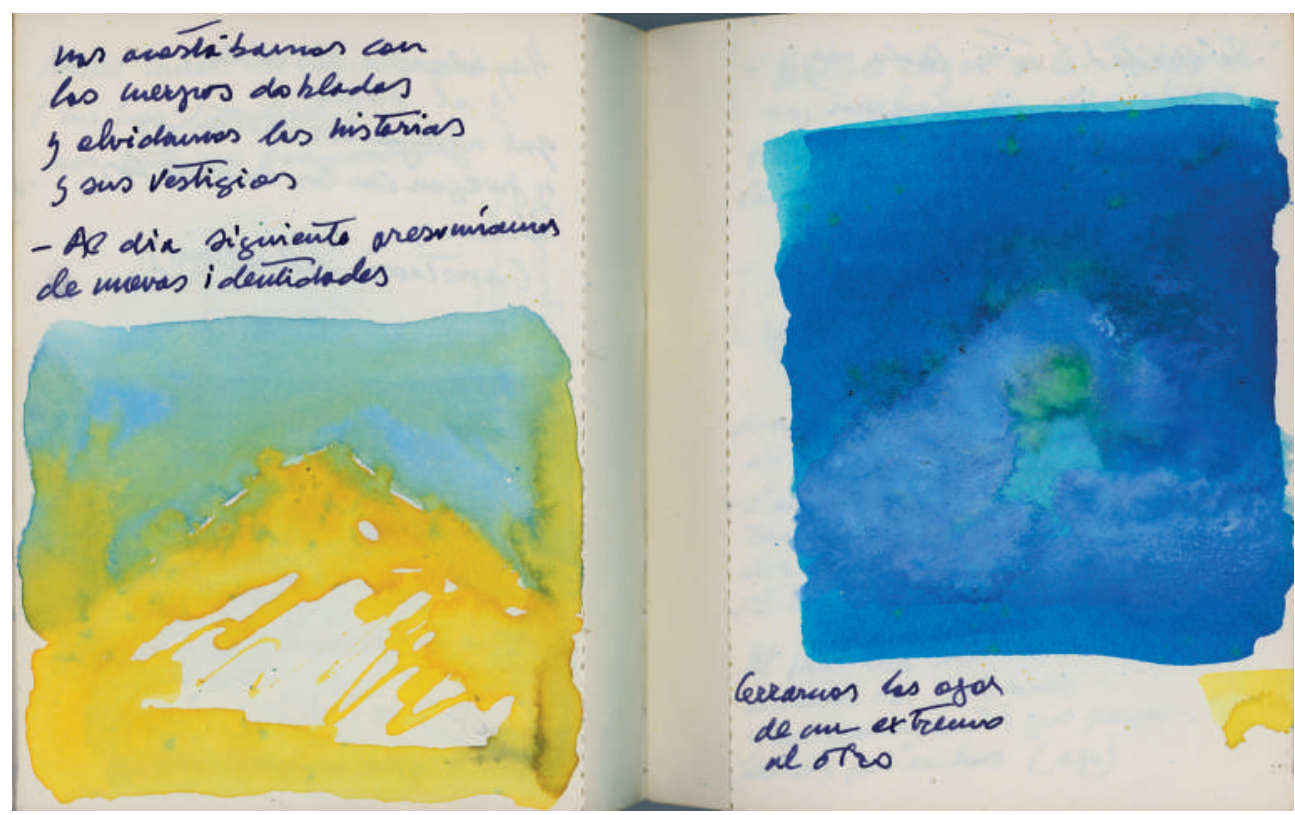

Rafael Hastings. Diario de Filmación, ca. 1974

contraste es dramático cuando dos colores complementarios, rojo y verde, azul y naranja o amarillo y violeta se colocan en yuxtaposición). En algunas anotaciones plantea formas coreográficas que busca asociar con la música de compositores como Mendelsson o Rachmaninoff. Tanto en la libreta como en testimonios de Hastings, se menciona que, usando Paracas de locación, se realizó el primer desnudo integral de un hombre y mujer en la historia del cine peruano.

Las películas fueron reveladas en FotoFilm de Madrid, donde el propio Hastings llevó el internegativo y realizó el trabajo de color y luz. Fueron presentadas en 1976 en Lima en el Cine Roma ante un público compuesto en su mayoría por amigos, y luego las presentó en Nueva York. Las películas fueron coprooducidas por Juan Barandiarán, propietario de la empresa Cinex S. A., con el fin de que circulen en salas comerciales, pero el Coproci (Comisión de Promoción Cinematofráfica de la Ley N. ${ }^{\circ}$ 19327) negó su exhibición debido a los desnudos. Al igual que sucedió con algunos de sus trabajos en video, este conjunto de obras fílmicas se encuentra con paradero indefinido.

Si bien a partir de 1980, Hastings se dedicó principalmente a la pintura, nunca descartó el video como un medio de expresión, principalmente para algunos trabajos que tienen que ver con el estudio del cuerpo, la coreografía y el performance, muchos en colaboración con su compañera, la bailarina y coreógrafa Yvonne von Mollendorff (Mariátegui, 2003).

El estudio de la obra de Hastings es un reto de investigación fascinante, pues requiere navegar por archivos para entender y reconstruir trabajos de producción efímera y situaciones que evitan el registro y la sistematización formal. Su campo creativo fue soportado por componentes plurisemióticos, que evaden las nomenclaturas artísticas establecidas y reta el trabajo historiográfico convencional. Su sorpresiva partida nos deja con una tarea inmensa, con muchas preguntas aún por responder, y nos reta a explorar y descubrir los rastros que ha dejado su rica y plurifacética producción. 


\section{Agradecimientos}

El autor agradece de forma especial y póstuma a Rafael Hastings, quien durante más de dos décadas tuvo la generosidad de dar a conocer su trabajo audiovisual y que, a partir de múltiples encuentros y correspondencia personal, facilitó detalles acerca de su obra, las cuales han sido clave para el desarrollo de esta investigación. El autor también agradece a Yvonne von Mollendorff y Manuel (Manongo) Mujica, quienes han permitido, a partir de sus testimonios personales, reconstruir muchos de los videos desaparecidos y el contexto de su producción. El profesor Alfonso Castrillón Vizcarra nos permitió establecer el primer contacto con la obra de Rafael Hastings, lo que permitió asegurar su recuperación y conservación. El trabajo de transcripción del diario de filmación fue realizado por Almendra Otta. Este trabajo se ha nutrido gracias al acceso a los archivos personales de Miguel López (Lima-San José) y Rodrigo Alonso (Buenos Aires), y los siguientes archivos institucionales: Archivos del Institute of Contemporary Arts: ICA (Tate Archives, Londres), Tate Archives (Londres), Archivos del Internationaal Cultureel Centrum (ICC) (Museum van Hedendaagse Kunst-HKA, Amberes), Palazzo dei Diamanti (Ferrara) y el Archivo del Museo Nacional de Bellas Artes (Santiago de Chile).

\section{Referencias bibliográficas}

Benjamin, W. (1986). "The Work of Art in the Age of Mechanical Reproduction". En: Hanna Harendt (ed.) Walter Benjamin: Illuminations. New York: Schocken Books.

Cytlak, K. (2017). "International Open Encounters on Video: the role of the Art and Communication Centre (CAYC) in Buenos Aires in international video art networks during the 1970s". En: Francois Bovier (ed.) Early Video Art and Experimental Films Networks. ECAL.

López, M. A. (2014). "El arte es bonito e interesante. Una conversación con Rafael Hastings". En: El futuro es nuestro y/o por un pasado mejor: 1983-1967. Lima: Instituto Cultural Peruano Norteamericano.

López, M. A. y Hastings, R. (2014). Rafael Hastings: el futuro es nuestro y/o por un pasado mejor, 1983-1967. Lima: Instituto Cultural Peruano Norteamericano.

Mariátegui, J.-C. (2003). Video-Arte-Electrónico-en-Perú 2.0. PERU/VIDEO/ARTE/ELECTRONICO: memorias del festival internacional de video/arte/electrónica. Lima: ATA / Universidad Ricardo Palma.

Mariátegui, J.-C. (2018). "Antecedentes: los inicios del video y los medios electrónicos en el Perú". En: El mañana fue hoy. 21 años de videocreación y arte electrónico en el Perú (1995-2016). Lima: M. Hernández Calvo, J.C. Mariátegui y J. Villacorta, ATA (Alta Tecnología Andina) y Ministerio de Cultura del Perú.

Noguera, M. (1967). "Pintor Peruano expone sus obras en Bruselas”. En: El Comercio. Lima.
Recibido el 25 de septiembre de 2020

Aceptado el 28 de septiembre de 2020 